\title{
Team-forming and its Impact in First Year Engineering
}

\author{
A.Trivett, C. Roy, Y. Sewlani \\ Department of Mechanical and Mechatronics Engineering \\ University of Waterloo, 200 University Avenue, Waterloo, ON N2L 3G1
}

\begin{abstract}
During the Fall 2014 term at the University of Waterloo, the first-year Mechanical Engineering course was re-designed to implement teambased learning. In order to improve student's job search chances, the method of team-forming was based upon the co-op hiring process. The first two weeks of tutorials were designed in a way that mirrored the co-op process and prepared students with resume writing and interviewing skills. This led to a significant increase in the number of students who received interviews, were ranked, and were hired by mid-semester. Attendance at tutorials improved, and timely assignment submission in a parallel course was improved. All of these measures indicated greater levels of student engagement compared with preceding cohorts.
\end{abstract}

Keywords: Team-forming, First-year Engineering, TeamBased Learning, Mechanical Engineering, Co-op Hiring.

\section{INTRODUCTION}

At the University of Waterloo, 200 first-year Mechanical Engineering students start their first co-op placement after only one or two semesters on campus. "ME 100: Introduction to Mechanical Engineering Part 1" attempts to familiarize students with engineering design, professionalism, communication, and engineering graphics. A re-design of this first course in Mechanical Engineering was needed to quickly prepare students for the job search, and to help build community within the ME cohort. ME100 was designed to create clusters of familiar faces for first-year students within their large class. This paper describes the team-forming model based upon the co-op hiring process, and presents measures of the impact on the class.

Similar to the course described by Gentili and Trevisan [7] for Electrical Engineering, ME100 was highly "process oriented", providing a focus on the team interaction, communication and the design process rather than a focus on the final product of a design.

The nested cluster approach is illustrated in figure 1 . On the right of Figure 1, 100 dots are shown in a grid. To the left, 100 dots are arranged in four large clusters, each with five small teams nested within them. The

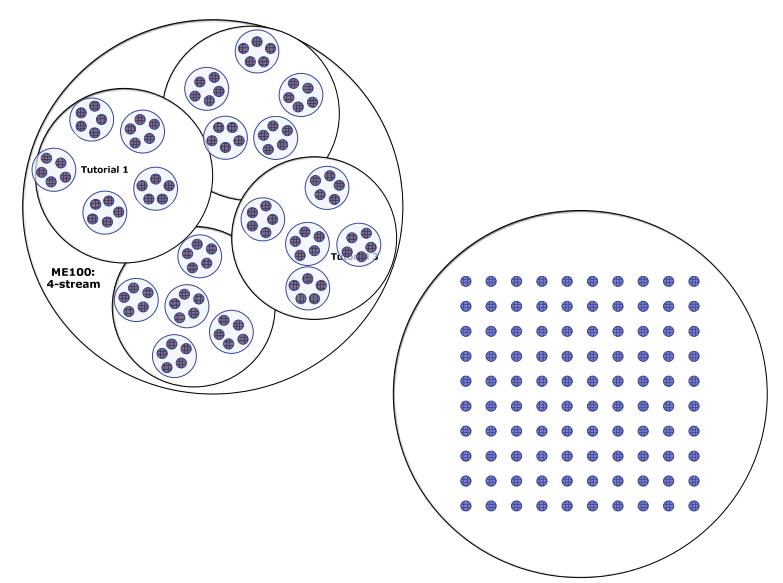

Figure 1: The circle to the right surrounds 100 dots arrayed in a grid. The circle to the left holds the same number of dots, but each is clustered in a way that it appears they are less crowded, and more individual. The image is a graphic to represent a class utilizing nested clusters of teams to enhance student individuality.

figure to the left appears as if there are fewer dots than to the right. In the same way, a large class broken into clusters makes it easier for students to identify with their colleagues, seeming as if the whole class cohort is smaller and more personal. As an instructor, the clustered class is easier in which to identify individuals, and recognize to which team and cluster a student belongs.

Benefits of Team-based Learning (TBL) are welldocumented. Michaelsen and Sweet [10] provided a guide to effective TBL but did not measure effectiveness or suggest methods for assessing impact of teams in an academic setting. Johnson et al [8] have presented a detailed measurement of the benefits to both students and instructors in a small programming class by considering the team Shared Mental Model (SMM) for skills acquired. The SMM used by Johnson et al incorporated performance measures related to several aspects of the team experience and course content. The measurement method provided more quantitative analysis than simple opinion surveys. This paper presents another set of objective measures of class behaviour that was related to 
team-forming and management which could help to bolster the conclusions of [10] and [8].

\subsection{Methods of Forming Teams}

There is a rich set of literature on different approaches to forming teams within university classes $[1,3,4]$. The methods for team forming range from random assignment, self-selection, personality test selection, experience-based selection, or grade performance based selection. Missing from the literature is interview-based selection, despite the reality that students are hired for coop positions using interviews that effectively result in assigned work-place teams.

Best practices for team-forming in the literature are largely based upon the authors' perceptions rather than upon performance measures [6]. However, Chapman [5] and Bacon et al. [2] have offered survey results to assess the impact of team-forming. Bacon provides detailed reports after asking students about their "best" and "worst" experience in team-work. The results indicate that team longevity is important, and that random selection for short-lived teams resulted in many of the "worst" experiences. Both studies report, while "random" seems fair, there is no evidence to suggest it makes for the best team experiences.

\subsection{ME100: Cornerstone Design}

ME 100 is divided into two sections: 1) Engineering Graphics and Design (EGAD) and 2) Design Communication and Professionalism (DCAP). The EGAD portion of the course introduces students to engineering design and drafting methods. The DCAP portion of the course teaches students how to effectively communicate design ideas and introduces them to their responsibilities as a professional engineer.

A similar course, MTE 100, is taught to students in Mechatronics Engineering in their first term at the University of Waterloo. Prior to the 2014/15 academic year, both ME 100 and MTE 100 were taught in a similar fashion, both with the EGAD portion as separate and parallel. EGAD section of both courses is taught by the same instructor. The topics and weekly assignments are the same for both courses, making it useful for comparison.

\section{CO-OP and TEAM SELECTION}

In first-year programs at the University of Waterloo, the Co-operative Education \& Career Action (CECA) deliver a one-hour lecture in the first week of classes. The session introduces the co-op program and online job search resources to new students. The same lecture is given to all programs in the faculty of engineering. This common information lecture does not allow for discipline-specific detail, or for any personalized help with resumes.

\subsection{ME100 during Week 1}

After the first one-hour lecture by CECA staff, a set of one-hour tutorials with each cluster of 25-30 students was facilitated by undergraduate Teaching Assistants (TAs). The students sat in small groups within their cluster and shared ideas for things to include on their own resumes. CECA staff and TAs circulated to offer guidance and answer questions.

Following the tutorial, students prepared a resume to share in the next class. Again, students were broken into their tutorial clusters where they exchanged resume drafts within ad-hoc groups.

By the end of the first week, students were required to submit their second drafts to an online discussion forum in the course management site. Just as in the classroom sessions, the online forums were constructed so that students shared only within their cluster, making the large class appear smaller to each individual student.

Once resumes were uploaded, students were given instructions on how to critique each other's resumes, and were told that they would be graded on the quality and quantity of feedback for the resume comments, not on the quality of their own resume. Suggestions were made regarding missed points, formatting, grammar, punctuation and more. TAs encouraged students who were struggling to seek help from CECA. Both this encouragement and peer-to-peer comments led to significant improvements from rough drafts to final versions.

By the end of the first week of classes, the activities in ME100 had allowed students to meet 25-30 of their classmates, read about the background of their colleagues, have two significant interactions with a single undergraduate TA, and develop their co-op resume. From the first week until the end of the term, each cluster was connected to the same TA. Students quickly got to know their TA, who became close with his cluster of students. Enthusiastic TAs were essential to the cluster structure.

\subsection{Team Forming in Week 2}

In week 2, the class received a list of job descriptions for members of an ideal design team (see Appendix A). They were told that team forming would follow a process similar to co-op hiring. Each student would meet, interview, and rank their classmates to be employed on "my design team."

In preparation for interviews, each cluster covered ways to prepare for an interview, common interview questions, and online resources. The tutorial had CECA staff present to provide support.

At the beginning of the large lab period, students met in their clusters for timed interviews, then went through a 4-minute speed-date cycle. One partner was the interviewer, another was the interviewee. Throughout this experience, students carried tally sheets to rank each other based upon their interview and resume. At the end 
of 2 hours of interviews, students submitted ranking sheets to the TAs. Each student had participated in 28 separate interviews, thus meeting one-on-one with everyone in their cluster.

On the ranking sheets, students marked the rank (1-5) for each of their interview partners. They indicated which team "job” they thought was appropriate for each interviewee. A section was included for students to list their top five 'dream team' members.

Ranking sheets were taken to a private room then sorted to identify the 5 students who were most highly ranked in each cluster. These students formed the base for each team. One person from each of these students' ranking was added to their team. This process was repeated until all the students had been assigned to a team. Each student was placed in a team with at least one other person whom they had ranked highly. Close attention was paid to prevent pairings where low rankings were given between two students.

Later the same day, team assignments were posted. Students seemed genuinely pleased with their assigned teams. Of 40 teams created in this way, each having 5-6 members, there was not a single complaint or request to change teams.

\subsection{Team Charter in Week 3}

Once teams were formed, students discussed individual roles in their team. Students generally agreed that the job descriptions were too narrow. Each team was instructed to formulate a "Team Charter". The Charter was a document signed by all members of the team which detailed their self-determined rules and policies. They were given no template for this, and, when asked, teaching staff encouraged students to put whatever policies they thought were needed.

The Team Charter was open for students to decide the terms of their contract. Most student teams addressed decision-making, intellectual property, expenses and discipline. All the student teams addressed attendance. A representative team charter states "If a team-member skips 3 or more team meetings, and/or 2 consecutive team meetings without notifying one other member of the group in advance, he/she risks being reported to the TA...." [11]

\section{RESULTS:}

Assessment of the impact from this method of team forming in ME100 is based upon four independent and largely external measures. The authors have not included the student opinion surveys, or any other survey results from students in favour of independent quantitative measures.

\subsection{Tutorial Attendance}

Tutorials were scheduled by the registrar before the semester in rooms which would hold $1 / 4$ of each of the 4

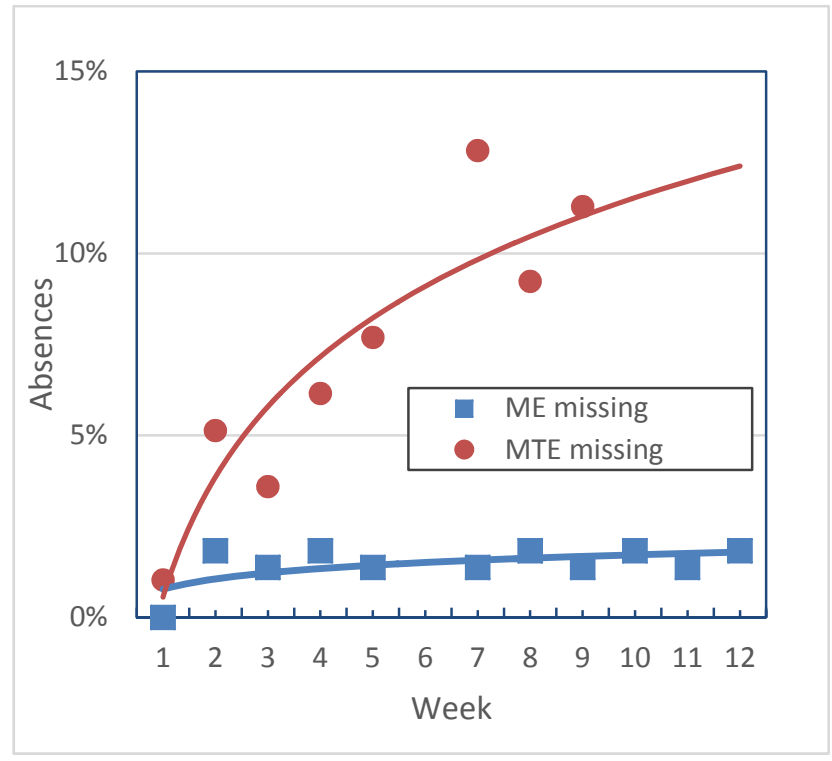

Figure 2: The plot shows student absences as percentage of the classes in both the ME and MTE class tutorials in Fall 2014. ME and MTE class sizes were similar.

classes (2 ME and 2MTE). Students began missing tutorials after the first week.

In the MTE100 tutorials, attendance was taken. Students were aware that grades were associated with their attendance. In contrast, ME100 attendance was recorded by the TAs who noted which teams did not have a full complement. Students in ME100 did not sign an attendance record, and no connection between attendance and course grade was ever suggested.

Figure 2 shows that the rate of absence was higher for MTE students as compared to ME students. Based upon the class sizes, this reflects 24 students skipping tutorials out of 195 in MTE each week versus 4 students out of 219 for the ME class in 2014. In the ME class, most of the tutorial sections had full attendance, and the 3 or 4 students not present were scattered throughout different teams. When asked by TAs about absent members, it was common for students to bring up their team charter policies that they were using to address the absences.

\subsection{Graphics Late Cards}

The EGAD portion of both ME100 and MTE100 is taught by the same instructor as a separate sub-course to more than 400 students in ME and MTE. Each of the 4 cohorts are nearly equal in size. Students complete weekly individual assignments, plus a midterm and exam. The workload for the weekly assignments is heavy, and has been largely the same for several years. The assignments are identical on a week-by-week basis for both ME100 and MTE100. 
To help reduce stress for students during the weeks of high work load, the instructor has given each student two "Late Cards" to use at any time. The Late Card allows students to have a 48 hour extension for their weekly assignment.

In past years, approximately half of the late cards have been redeemed by students. In 2013, the ME class redeemed 237/448 (53\%) late cards while the MTE class redeemed 152/282 (54\%) late cards available. In 2014, the MTE class redeemed 190/390 (49\%) late cards.

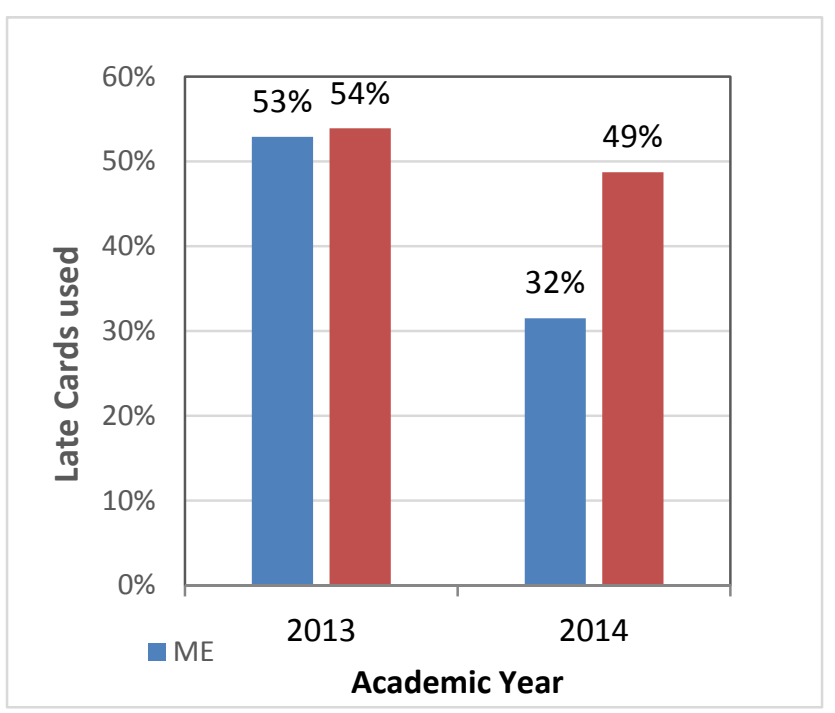

Figure 3: The figure shows comparison of use of Late Cards for the EGAD assignments in both ME100 and MTE100. A significant drop in card use was seen in F14 for ME100.

However, the use of late cards by the ME class in 2014 was significantly reduced to only $138 / 438$ (32\%) of the available late cards.

\subsection{Co-Op Hiring Rates}

The Co-op job search is a major stressor for first-year students. While more than 95\% of students seeking Coop placement indeed find something before the start of their co-op semester, having a job by mid-term relieves a great deal of pressure for a student, allowing them to focus on courses.

When recruiting co-op students, employers typically interview students from many programs for the same position. A comparison of the hiring rate for ME students with the rates for other programs in the faculty is a realistic comparison between ME students and their pool of competitors.

The initial "fixed round" of job searches conclude with a "match day" on October 30 each year. A student receiving a match may then accept or reject the position. If the student ranked first by the employer declines, then the position is automatically offered to the next ranked student for the job. Being "ranked" is an important measure for students co-op chances.

Table 1 shows the comparison of the percentage of the class that was hired by match day. This data represents only the employers' top choices. The ME data is for the first-semester students looking for placements in January. The data for "Other Engn" includes all students from $1^{\text {st }}$

\begin{tabular}{|c|c|c|c|c|}
\hline \multirow{2}{*}{ Table 1 } & \multicolumn{2}{|c|}{ Oct-13 } & \multicolumn{2}{c|}{ Oct-14 } \\
\cline { 2 - 5 } & $\begin{array}{c}\text { FY } \\
\text { ME }\end{array}$ & $\begin{array}{c}\text { Other } \\
\text { Engn }\end{array}$ & $\begin{array}{c}\text { FY } \\
\text { ME }\end{array}$ & $\begin{array}{c}\text { Other } \\
\text { Engn }\end{array}$ \\
\hline \# applicants & 112 & 2255 & 96 & 2513 \\
\hline Employed & $12 \%$ & $29 \%$ & $24 \%$ & $31 \%$ \\
\hline Interviewed & $42 \%$ & $63 \%$ & $49 \%$ & $64 \%$ \\
\hline Ranked & $72 \%$ & $80 \%$ & $89 \%$ & $82 \%$ \\
\hline
\end{tabular}

to $3^{\text {rd }}$ years in all engineering programs. It is typical that the hiring rates are lower for $1^{\text {st }}$ year ME students than senior students. It is clear that the hiring rate on match day in 2014 was nearly double what it was the previous year. The hiring rate for all other students in the faculty was the same from 2013 to 2014.

To be interviewed, and then ranked by an employer is a boost to the student's confidence. Comparing 2013 and 2014, there was an increase of interview rate (42\% of 2013 class to $49 \%$ for the 2014 class). The interviews were selected by the employers from resumes submitted during the first two weeks of the semester. Only the ME class engaged in the resume review and revisions described in section 2 .

In 2013, 72\% of ME students interviewed were ranked by employers. In 2014, 89\% of first-year ME students receiving interviews were ranked. Clearly, the employers responded to the 2014 class by choosing their resumes more frequently, and considering their interviews to be more acceptable than in 2013.

\section{DISCUSSION}

It is hard for faculty to know what truly goes on inside a student team. The measures presented here showed external effects of the team-forming process reflected in higher co-op employment statistics, in greater attendance, and in a lesser need to submit assignments late for a parallel course.

The ME100 students, through the method described in this paper, were formed into 8 separate clusters each with 5 teams. The teams existed for the entire 12-week semester. Through the semester, teams engaged in a challenging open-ended conceptual design project.

Of the 40 teams, there were 2 who felt it necessary to approach one of the two professors in the course for help with team issues. These were either a team member had 
stopped contributing, or a team member significantly disagreed and was destructive to the team.

The most telling question might be whether or not students would choose to work together again. For half of the class, a follow-on course began in January. In this class, students were required to make new teams. The registrar had placed the new ME101 class into two separate sections which bore no connection with the ME100 clusters. Since students were only able to form teams within their new ME101 clusters, many students were in fact orphaned by their place in the new class

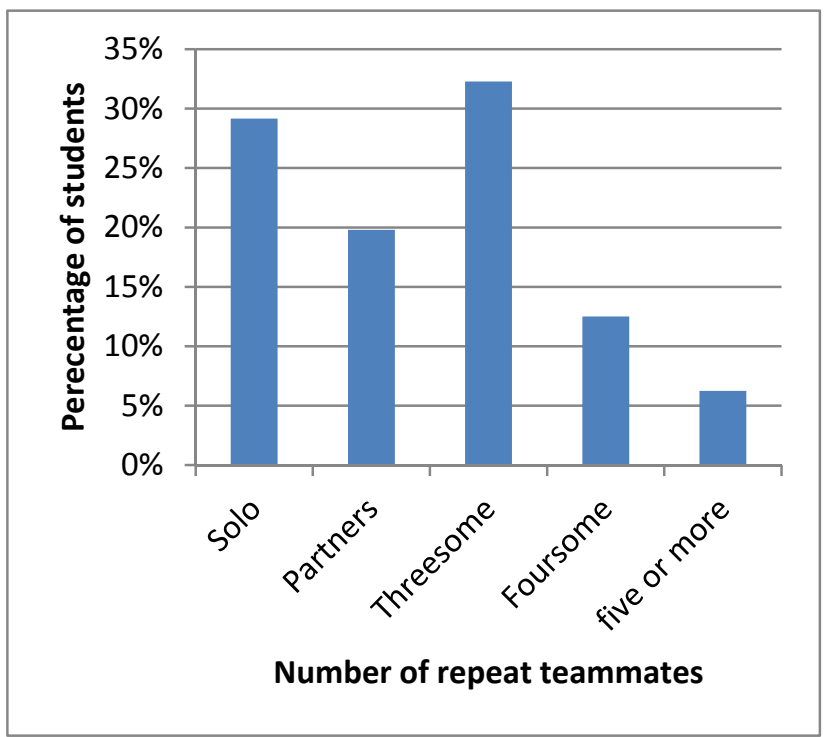

Figure 4: The figure presents the percentage of the class who, in second semester, chose to work with members of the same team that they were assigned in ME100.

sections. Students were actively discouraged from signing up the same teams.

Figure 4 shows the makeup of ME101 teams compared with the team makeup from ME100. Of the students who had participated in ME100, the majority of the class chose to form teams with two or more members from their previous semester. These groupings, in a number of cases, consisted of three students from one team joining up with 2 students together from a different team. Thus, the students, even when discouraged actively by the teaching staff and the registrar from re-forming their teams from first semester chose to regroup.

\section{CONCLUSION}

The work presented here shows the impact of a specific method of team assignment in a large first-year engineering class. Measures used to assess impact of the changes were comparison of:

- attendance records of students in a parallel course

- "late cards” between two parallel programs
- employment rates on Match Day

- $\quad$ student choice for re-selection team members.

ME students in the Fall 2014 term had a higher tutorial attendance, and a lower use of late cards than a parallel cohort in a non-team based course. The extensive use of teams in ME100, and specifically the teams development of their own rules of governance allowed students to police their own attendance, and thus their level of engagement.

The majority of the students chose to work with the same students as they "hired" in their first semester teams when re-formed in a subsequent course. Despite a challenging workload, the teams that were formed evidently had a successful bonding experience.

The process of using interviews and resumes to rank complementary students in teams appears to have been effective in producing teams with very low attrition, and a very low number of internal team conflicts.

Finally, the use of practice and peer-criticism in development of resumes and interview skills appears to have resulted in an improvement in first-year co-op hiring for the Mechanical Engineering class.

\section{Acknowledgements}

Thanks to Jen Woodside and staff at the CECA for providing essential employment statistics, to Prof. James Baleshta and Dr. William Melek for providing access to their course data.

\section{References}

[1] Bacon D. R. et al., "Methods of assigning players to teams: a review and novel approach", Journal of Simulation and Gaming, v.32 (1), p.6, 2001.

[2] Bacon D. R. et al., "Lessons from the best and worst student team experiences: How a teacher can make the difference”, Journal of Management Education, v.23 (5) , p.467, 1999.

[3] Blowers P. , "Using student skill self-assessment to get balanced groups for group projects”, College Teaching, v.50 (3) , p.106, 2003.

[4] Borges, J., T. Dias and J. Cunha, “A new group-formation method for student projects”, European Journal of Engineering Education, Vol. 34, No. 6, December 2009, 573-585.

[5] Chapman K. J. , “Can't we pick our own groups? The influence of group selection method on group dynamics and outcomes”.. Journal of Management Education, v.30 (4) , p.557, 2006.

[6] Delson N. J., "Increasing team motivation in engineering design courses”, International Journal of Engineering Education, v.17 (4, 5) , p.359, 2001.

[7] Gentili, K.L.; Trevisan, M.S., "A process oriented class in engineering design: how it works," Frontiers in Education 
Conference, 1997. 27th Annual Conference. Teaching and Learning in an Era of Change. Proceedings. , vol.2, no., pp.972,980 vol.2, 5-8 Nov 1997

[8] Johnson T.E., E. Top, E. Yukselturk, “Team shared mental model as a contributing factor to team performance and students' course satisfaction in blended courses “, Computers in Human Behavior, November 2011, Volume27 (Issue6), pp.2330-2338

[9] Melek, W, MTE 100: Introduction to Mechatronics Engineering Course Outline, University of Waterloo, 2014.

[10] Michaelsen L.K., M. Sweet, “The essential elements of team-based learning”, New Directions for Teaching and Learning, 2008(116), pp.7-27.

[11] Trivett, A. and Collins, M., ME 100: Introduction to Mechanical Engineering Course Outline, University of Waterloo, 2014. 


\section{APPENDIX A:}

\section{ME100/101: MECHOSYSTEM TEAM MEMBERS}

This term, the class will be divided into teams of 5. In order to have an effective team, you need a variety of people who can work together to be successful in all areas of the MechoSystem design process. Each team will have 5 roles with different personalities - a manager, a communicator, a theorist, a builder, and a generalist. As with any small startup enterprise, nobody can exclusively fill just one role, but it is best to find teammates where there is a complementing of abilities. Many of the duties required of members in a small team overlap, and the best teams work to everyone's strengths. Each team member is expected to contribute equally to every assignment, and to every area of work.

Manager: A manager is good at coordinating duties related to the project, and must be able to keep all team members fully engaged, and working towards a common goal. This person will be respectful, encouraging, inspiring, personable, and able to demonstrate a number of ways to keep the team on track. This is not the "boss" or "leader" of a team, rather this person is the helper to smooth out any personality conflicts, arguments, and keep everyone working. They are the sort of person who can make you laugh and want to pull together, but doesn't waste your time.

- Self-motivated, and be capable of motivating others

- Flexible to opinions, and open to ideas

- Attention to detail in all areas of work

- Organized with good time management skills

- Good report writing skills

Communicator: A communicator is comfortable sharing ideas with others verbally and in writing. This is the sort of person who listens to what others have to say, then is quickly able to distill that into a clear explanation or story. A communicator will be happy ensuring the team ideas are clear, and can provide support to other team members with their individual written, verbal, and graphical communications.

- Excellent communication skills, both verbal and written

- Confident, comfortable talking in front of a group

- Can write easily and efficiently as required

- Exceptional grammar

- Great Listener

Theorist A theorist excels when analyzing a situation from a mathematical, or scientific perspective. They can easily relate real life situations to scientific principles. Data analysis is a breeze. They do not struggle with theories that have no literal interpretation.

- Can easily understand new applications of theory,

- Proficient in data analysis, and creating graphs

- Strong ability to connect theory with reality

- Good at explaining knowledge to others
Builder A builder enjoys engineering from the hands-on perspective. They would rather solve problems by dealing with physical objects, and letting their observations solve the problem, instead of dealing only with mathematical models and simulations. Builders have a practical feel for tools and materials, and enjoy the physical assembly of their designs as much as the design process itself.

- Familiar with many tools, and manufacturing

- Excels in CAD and sketching

- Experience with mechanical and electronics

- can easily make things

- Good at explaining things to others

Generalist A generalist does not necessarily specialize in any of the areas listed so far, but they have many of the characteristics listed above. They are capable and willing to do anything the team needs. This team member thinks always of the team's success, and is always ready to help anyone in need. They are fundamentally generous with their time and energy, and feel best when everyone is doing their best. They'll do anything it takes for the project to succeed.

- A general understanding of all the areas listed above

- Easygoing, flexible, works with the group, or alone

- A fast learner, move quickly between tasks

- Always sees the bigger picture of a project

- Great sense of humor, and a thick skin 